\title{
Research on modified incremental pushover analysis considering dy- namic characteristics of damaged structures
}

\author{
X.L. ZHOU, H.L. LU, Z. TANG \& Y. YE \\ Wuhan Institute of Technology, Wuhan, China
}

\begin{abstract}
KEYWORD: Damaged structures; Seismic performance; Evaluation method; Target displacement; Inter-story drift

ABSTRACT: IDA need elastic and plastic analysis of the structure with a large number of different intensity ground motion inputs and had some disadvantages such as high cost of computation, retraction and non-monotonicity of its curve. An improved method of static elastic-plastic analysis with the consideration of incremental idea and structural dynamic characteristics was presented. Calculation expressions of lateral force loading mode and target displacement based on the modal combination were derived considering combination of modal lateral forces for pushover analysis, and some implementation steps of seismic performance evaluation of structures based on DIPA method were given. Accuracy and effectiveness of DIPA method were verified by an example of a 5 story reinforced concrete frame structure. DIPA analysis method changed quantity and mode of vibration mode combination, it had consideration of the influence of high mode and acquisition of accurate calculation results, also the effect of DIPA analysis method was consistent with IDA method. It was capable of reflecting the real seismic response of the structure with simple calculation process and less computational cost.
\end{abstract}

\section{INTRODUCTION}

The traditional push over analysis method is able to express development process of internal force and deformation of structure from elastic process to ultimate collapse process, with simple calculation process and low calculation cost sometimes it even can get more information than the time history analysis and it is one of the important methods to evaluate the seismic performance of structures at present.( Bai,2016; Chopra, 2002 )However, its accuracy is limited by two basic assumptions, it can not truly reflect the mechanical behavior of the structure under strong earthquake and the influence of various seismic wave input on the seismic performance of the structures, that makes it unable to replace the dynamic elastic-plastic analysis method.( Azimi, 2009; He,2016) Especially after the structure enters the plastic stage, the results of static analysis have much to do with the extent of structural damage, The applicability and reliability of the pushover analysis method are greatly improved if we can find a modified method of pushover analysis which can not only consider the dynamic characteristics of the structure, but also possess the basic functions and advantages of both static analysis and dynamic analysis.

However, the improved pushover analysis method in essence is still belongs to the static elasticplastic analysis method, the validity and the accuracy of analysis method need to consider four issues: 1)How to ensure the target displacement in structure under different earthquake; 2)How to consider the effect of higher modes on the structural seismic performance; 3)How to consider the effects of ground motion characteristics on structural seismic performance; 4)How to consider the dynamic characteristics of the structure, especially the change of the dynamic characteristics of the structure damage.

On the basis of the above mentioned consideration, this paper presents a method considering the dynamic characteristics of incremental pushover analysis(DIPA), which is used for seismic performance evaluation of damaged structures. A 5 story frame structure is taken as an example to verify the validity and accuracy of this method.

Determination of lateral force loading mode and target displacement based on modal combination The real response of the structures under the effect of earthquake can be determined by each modal combination of structure. when using modal combination to calculate seismic response, the contri- 
bution of $n$-th mode to floor nodal displacement $X(t): X_{\mathrm{n}}(t)=\phi_{\mathrm{n}} q_{\mathrm{n}}(t)$ where: $\phi_{\mathrm{n}}$ is $n$-th mode of structure. The total displacement of structural each modal combination is considered: $x$

$$
\boldsymbol{x}(t)=\sum_{n=1}^{N} \boldsymbol{X}_{n}(t)=\sum_{n=1}^{N} \phi_{n} q_{n}(t)
$$

Equivalent static load: $f(t)=K x(t), K \phi_{\mathrm{n}}=\omega 2 n M \phi_{\mathrm{n}}$, lateral load is expressed as,

$$
f_{\mathrm{n}}(t)=\omega 2 n \mathbf{M} \phi_{\mathrm{n}} q_{\mathrm{n}}(t)
$$

The elastic plastic displacement response of the structure can only be considered in the model of the second and third order before the earthquake can reach a better precision (Azimi, 2009). As following expression(3)and(4):

$$
\begin{gathered}
x_{r}(t)=\sum_{n=1}^{N} \phi_{r n} q_{n}(t)=\phi_{r 1} q_{1}(t)+\phi_{r 2} q_{2}(t)+\mathrm{K} \\
f_{\mathrm{s}}(t)=\omega 21 \mathbf{M} \phi_{1} q_{1}(t)+\omega 22 \mathbf{M} \phi_{2} q_{2}(t)+\ldots
\end{gathered}
$$

Making vibration mode $\phi_{\text {ri }}$ standardization and top displacement coordinate of each vibration mode $\phi_{\mathrm{rn}}=1$, (3)can be simplified:

$$
x_{\mathrm{r}}(t) \approx x_{\mathrm{r} 1} \cdot\left[1+q_{2}(t) / q_{1}(t)+q_{3}(t) / q_{1}(t)\right]
$$

Because push-over analysis is that the lateral load is gradually increased from zero to the structure to achieve the target displacement. Considering the model of lateral load distribution based on modal combination, (4)can be simplified:

$$
f_{\mathrm{s}}(t)=\omega 21 \mathbf{M} \phi_{1}+\omega 2
$$

$2 \mathbf{M} \phi_{2} \cdot\left[q_{2}(t) / q_{1}(t)\right]+\ldots$

Can be seen from (5) and (6), $x_{\mathrm{r}}(t)$ and $f_{\mathrm{s}}(t)$ are related to $q_{i}(t)$. And the maximum displacement response of each mode is not happened at the same time.in order to eliminate time parameter, according to random vibration theory, by using the formula to determine the maximum seismic response of the structure, the SRSS combination method can be used. And the ABSSUM combination method can be used to combine the vibration mode when the horizontal lateral force is determined:

$$
q_{j}(\mathrm{t}) / q_{1}(\mathrm{t})=\left|\Gamma_{j} \mathrm{D}_{j} / \Gamma_{1} \mathrm{D}_{1}\right|
$$

Where: $\Gamma_{j}$ is $j$-th mode participation factor of structure, $\Gamma_{j}=\boldsymbol{\Phi}_{j}^{\mathrm{T}} \boldsymbol{M I} / \boldsymbol{\Phi}_{j}^{\mathrm{T}} \boldsymbol{M} \boldsymbol{\Phi}_{j}, \mathrm{D}_{j}$ is Corresponding displacement of $j$-th mode based on Calculation of seismic wave elastic displacement spectrum Substitute (7) into (5)and(6), it can be concluded:

$$
\begin{gathered}
x_{\mathrm{r}}=x_{\mathrm{r} 1} \sqrt{1+\left(\Gamma_{2} D_{2} / \Gamma_{1} D_{1}\right)^{2}+\left(\Gamma_{3} D_{3} / \Gamma_{1} D_{1}\right)^{2}+\mathrm{L}} \\
f_{\mathrm{s}}=\omega 21 \mathrm{M} \phi_{1}+\omega 22 \mathrm{M} \phi_{2}\left|\Gamma_{2} \mathrm{D}_{2} / \Gamma_{1} \mathrm{D}_{1}\right| \\
+\omega 23 \mathrm{M} \phi_{3}\left|\Gamma_{3} \mathrm{D}_{3} / \Gamma_{1} \mathrm{D}_{1}\right|+\ldots
\end{gathered}
$$

$D_{i}$ is based on elastic displacement response spectrum in (8) and (9). Elastic displacement response spectrum corresponding to each seismic wave transformed from $S_{\mathrm{de}}=\left(1 / \omega^{2}\right) \cdot S_{\mathrm{a}}=\left(\mathrm{T}^{2} / 4 \pi^{2}\right) \cdot S_{\mathrm{a}}$ 。 Elastic displacement response spectrum is determined by the relationship between $u \mathrm{~m}$ and $u 0$

Three different combinations of lateral load modes are obtained by (9). Only considering the lateral load mode is called mode(1). Considering the lateral load modes with the first two order modes of combination, called mode $(1,2)$. Considering the lateral load modes with the first three order modes of combination, called mode $(1,2,3)$.

DIPA implementation steps of considering ground motion characteristic

Seismic performance of structure damage assessment of the need for accurate evaluation of the damaged structure under the different earthquake intensity seismic capacity and seismic demand, the traditional static push pushover analysis method can't meet this requirement. Taking into account the impact of different seismic input on the seismic performance of the structure is the accurate determination of the structural target displacement that is the point of performance. DIPA analysis method select 10 to 20 seismic waves based on site characteristics and dynamic characteristics of structure and monotonic amplitude modulation of each seismic wave is based on Incremental idea, and the structure of equivalent SDOF system history analysis, top displacement $x_{\mathrm{r} 1}$ of equivalent SDOF system in each seismic wave of different strength input. 
Ability family of curves DIPA analysis method based on statistical analysis methods

According to the method of determining the lateral force loading mode given in the previous section and top displacement, you can acquire a different variation of the intensity of ground motion input structural performance indicators, due to the different characteristics of seismic waves greater impact on the seismic performance of structures, that is, different structural response of seismic wave input obtained discrete large, it is difficult to assess the actual earthquake engineering. In order to examine the degree of dispersion of data, data processing are usually used in many IDA curve of probability and statistics methods, then analysis it vulnerability. The traditional direct time history analysis IDA family of curves obtained of structure tend to have "non-monotonic", "back off" and "platform stage" and so on[4], so that these curves vulnerability analysis has some limitations. In order to reduce the error caused by these factors, scholars often use different mathematical processes, such as processing method based on Bayesian theory, and these methods will undoubtedly further increase the complexity of IDA analytical process. The core idea of DIPA considering the structural dynamic properties and the seismic waves properties is that the method first analyzed the equivalent single degree of freedom system by IDA, and capturing structure target top displacement, then based on reasonable lateral force distribution pattern of structure pushover analysis, analysis by DIPA family structural capacity curve obtained by the above problem does not exist. Thus, the structure damaged by the earthquake vulnerability analysis curve results DM-IM available DIPA as the basis for analysis.

Structural seismic vulnerability analysis and calculation methods to project requirements for variable parameters(Zhou, 2014):

$\left.P(E D P) \geq L S_{i} \mid I M=x\right)=1-\Phi\left[\ln \left(L S_{i}-\mu\right) / \sigma\right]$

In the formula, $\mu, \sigma$ represent logarithmic mean and standard deviation under EDP when IM=x, IM describe earthquake intensity index strength. Vulnerability analysis and calculation method to seismic ground motion intensity parameters as variables are:

$$
\left.P(E D P) \geq L S_{i} \mid I M=x\right)=\Phi[\ln (x-\theta) / \beta]
$$

In the formula, $\theta 、 \beta$ represent the logarithmic mean and when the difference between logarithmic standard when $E D P=L S_{i}$

\section{IMPLEMENTATION STEPS FOR SEISMIC PERFORMANCE EVALUATION BASED ON DIPA}

The implementation steps of seismic performance evaluation for DIPA method

According to the above analysis, implementation steps of seismic performance evaluation of damaged structure based on DIPA are shown in Figure 1. 


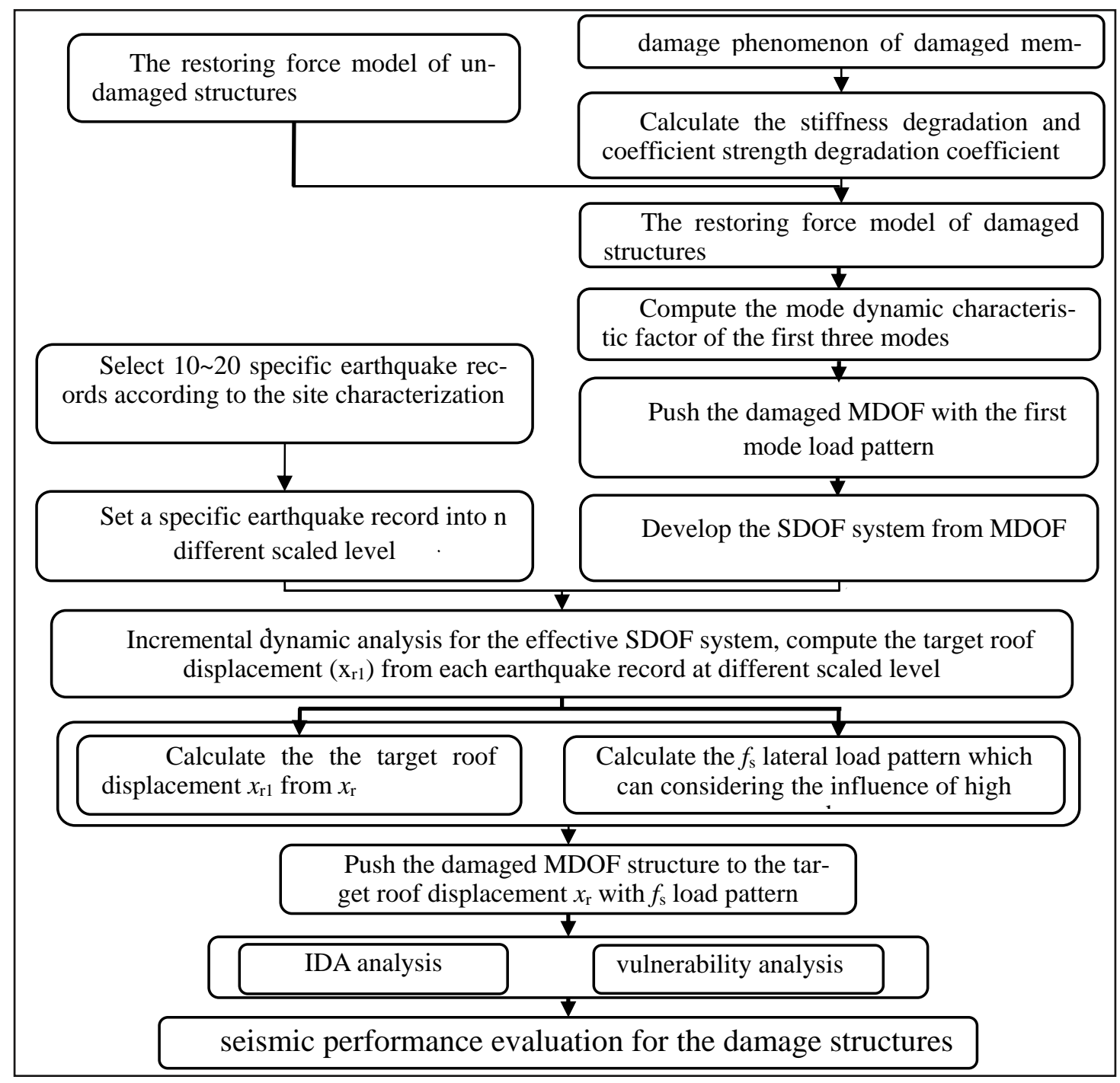

Figure 1 The implementation steps of seismic performance evaluation for DIPA method

\section{Determination of seismic performance evaluation and analysis model of damage structure}

DIPA analysis method based on seismic performance evaluation for structure requires to determine the structure of the numerical calculation model firstly. Existing research results show that, damaged members hysteretic bone curve are the same with intact members hysteretic bone curve in form. It can be considered damaged members and intact members in the descending portion of hysteretic bone curve have the same stiffness; and that two yield components after rising portion stiffness is also consistent. As assumption above, the core problem of hysteretic bone curve of damaged members can be transformed into the initial stiffness and strength decrease value in the hysteretic bone curve of damaged and intact members are determined.

The author gives damaged members numerical value of stiffness and strength degradation $\alpha_{\mathrm{k}}, \alpha_{\mathrm{F}}$ on different damage index DI in document 6(Zhou, 2014), and gets fitting relation of $\alpha_{\mathrm{k}} 、 \alpha_{\mathrm{F}}$ and DI by using the regression method. As (12), (13) shows:

$$
\begin{aligned}
& \alpha_{\mathrm{k}}=0.11687(D I)^{-0.71654} \\
& \alpha_{\mathrm{F}}=1-0.527(D I)^{1.52}
\end{aligned}
$$

\section{EXAMPLE ANALYSIS AND VALIDATION}

\section{Design and description of model}

To verify the effectiveness of the DIPA analysis method, the paper designs a 5-story RC frame structure. The result of calculating by paper method is compared with that by time history analysis method on different seismic input. This paper select a frame in analysis for calculation, As Figure 2 
shows that load arrangement and matching bar condition. Concrete strength grade of beam and column are C35. longitudinal tensile bar are HRB400. Stirrup are HPB300. 8-degree seismic fortification intensity, Site II class 1 groups, Structure specific load information are given in the table2.

Table 2. Structural load information

\begin{tabular}{|c|c|c|c|c|c|c|}
\hline \multirow{4}{*}{$\begin{array}{l}\text { Structure } \\
\text { position }\end{array}$} & \multicolumn{2}{|c|}{$\begin{array}{c}\text { Uniformly dis- } \\
\text { tributed } \\
\operatorname{load} /(\mathrm{kN} / \mathrm{m})\end{array}$} & \multicolumn{3}{|c|}{ Concentrated } & load/kN \\
\hline & \multirow{3}{*}{$\begin{array}{l}\text { dead } \\
\text { load }\end{array}$} & \multirow{3}{*}{$\begin{array}{l}\text { Live } \\
\text { load }\end{array}$} & \multicolumn{2}{|c|}{ Edge node } & \multicolumn{2}{|c|}{ Inside node } \\
\hline & & & dead & live & dead & live \\
\hline & & & load & load & load & load \\
\hline top floor & 12.09 & 1.1 & 121 & 7 & 149.6 & 10.6 \\
\hline $\begin{array}{l}\text { Middle } \\
\text { floor }\end{array}$ & 9.35 & 4.4 & 102.3 & 28.1 & 122.9 & 42.5 \\
\hline $\begin{array}{l}\text { The 1st } \\
\text { floor }\end{array}$ & 9.35 & 4.4 & 105.4 & 28.1 & 126 & 42.5 \\
\hline
\end{tabular}
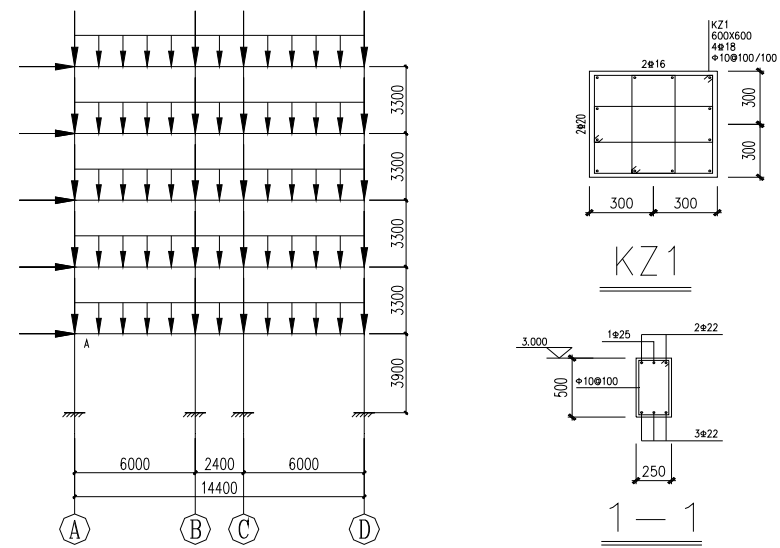

Figure 2 Elevation and reinforcement figure of a frame

Condition selection and calculation result analysis

It is given that lateral force load patterns and calculation method of target displacement by(8) and(9). The author design three conditions: mode(1)、 mode(1,2)、 mode(1,2,3). They Were used to consider the effects of first order mode, two order modes and three order modes and compared with time history analysis. To avoid the effect of seismic wave input IDA on the analysis results, this paper calculate IDA curve result of structure on 13 seismic wave input. seismic intensity measure is $\mathrm{Sa}(\mathrm{T} 1)$ and get $50 \%$ percentage value curve. According to seismic performance evaluation implementation steps of DIPA in the previous paper, the incremental relation curve of the maximum inter-story displacement angle of each story of the structure under the three conditions is obtained. It should be pointed out that calculation model of 5-story RC frame is used The effects of high order mode are mainly reflected upper part in the middle of structure,4 5story. To facilitate comparative analysis, the incremental numerical results of first-floor, second-floor and fourth-floor, fifth-floor inter-story displacement angle were extracted in this paper, as figure 3 shows.

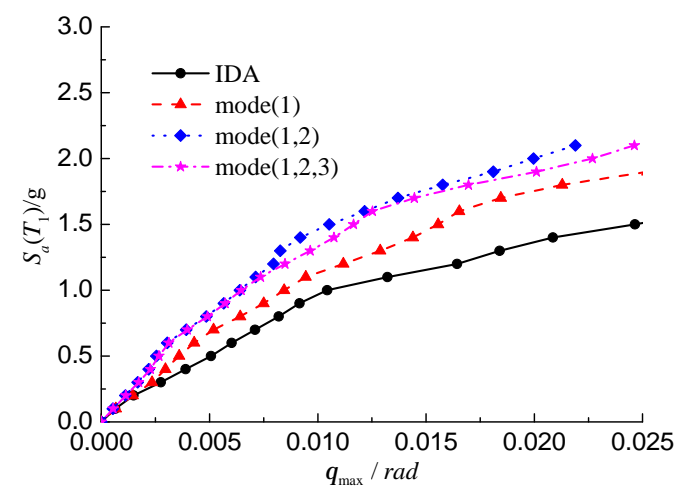

(a) inter-story displacement of first floor 


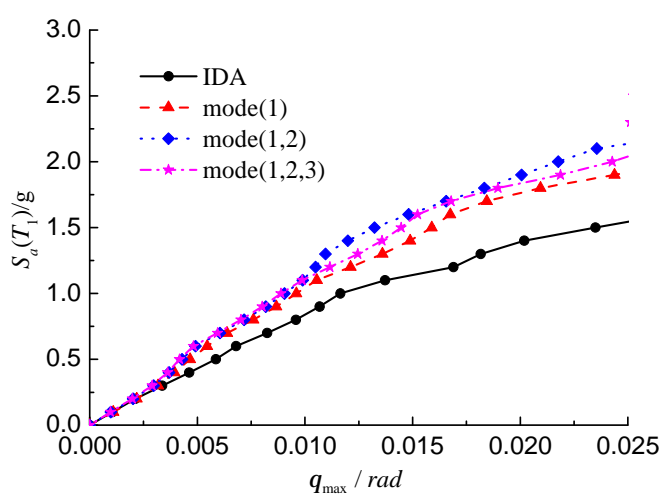

(b)inter-story displacement of second floor
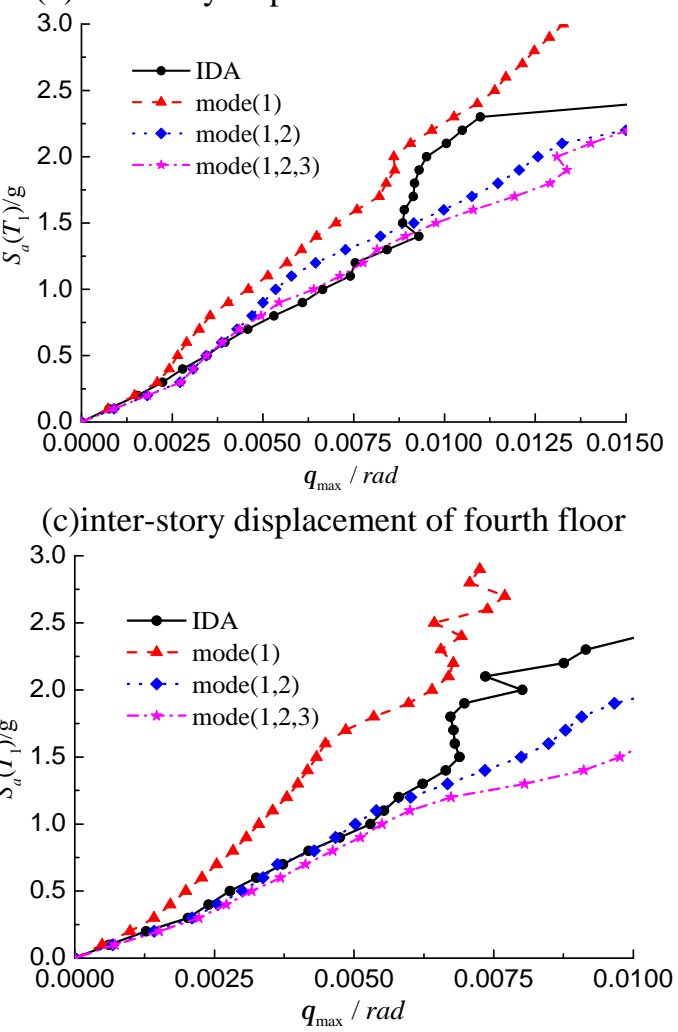

(d)inter-story displacement of fifth floor

Figure 3 The comparison of IDA curve of the inter-story displacement angle on different conditions

By comparing and analyzing inter-story displacement angle of each story in Figure 3 in the IDA analysis method and the calculation results of the DIPA analysis method in this paper can be drawn: (1) The structure IM-DM curve obtained by the DIPA method in this paper is consistent with the curve obtained by the IDA analysis method, which shows that the improved method can effectively evaluate the response of the structure under earthquake. (2)DIPA analysis method can be defined as incremental dynamic push over analysis, but the calculation process is more simple, and can avoid the IDA curve statistical analysis of the fold back, not monotonic and other defects. (3)The IM-DM curve obtained by the DIPA analysis method is in the left side of the curve obtained by the IDA method On lower floors(first-floor, second-floor), the structural damage index calculated by the DIPA analysis method under the same earthquake intensity is less than the real value, because DIPA analysis method is that maximum seismic response of equivalent SDOF system is obtained by elastic displacement response spectrum of seismic waves, that causes error between calculated result and practice in calculation example of this paper. (4)in higher floors(fourth-floor, fifth-floor), when only considering the 1 order mode of the operating condition 1, calculation results is different from the real one. when considering the higher order mode of the operating conditions 2and3, calculation results is very close to real one. It shows that the DIPA can effectively simulate the real seismic 
response of the structure. Especially the obvious effect of higher modes, the DIPA method is accurate and effective about them.

\section{CONCLUSION}

This paper presents an incremental improvement pushover analysis method (DIPA) which considers dynamic characteristics, combines the basic functions and advantages of pushover analysis and IDA. Derivation of calculation process and concrete procedure are given in this paper. Finally, it set an example to verify the accuracy and effectiveness of DIPA method:

(1)DIPA can accurately and efficiently evaluate the structure's seismic response.

(2)DIPA can be considered as an incremental pushover analysis method that the effect of the method is consistent with IDA, but the calculation process of the method is much more easier, it also avoid the meander and the non-monotonicity when IDA curve is statistical analyzed, computational cost and storage space are reduced to a large extent as well.

(3)DIPA is able to determine the number of modal combination according to the extent of structural participation in each mode. If multistory buildings is hardly affected by high order modes, DIPA considers the combination of the first and the second order mode participation. DIPA considers the combination of the first three order modes participation, if high-rise buildings is easily affected by high order modes.

\section{ACKNOWLEDGEMENTS}

This work was financially Supported by the National Natural Science Foundation of China (Project No. 51378404), the natural science foundation of hubei provincial department of education (Project No.) and the scientific research foundation of wuhan institute of technology (Project No. K201474).

\section{REFERENCE}

[1] Bai J L\&Ou J P. 2016. seismic performance evaluation of structures considering the combination of modal lateral forces for pushover analysis .Engineering Mechanics33, 58-66.

Chopra A K\&Goel R K. 2002. A modal pushover analysis procedure for estimating seismic

[2] demands for buildings . Earthquake Engineering \& Structural Dynamics. 31(3): 561-582.

Azimi H\& Galal K\& Pekau O A. 2009. Incremental modified pushover analysis The Structural Design of Tall and Special Buildings. 18(8): 839-859.

[3] He Y B\&Deng P\&Zhang C. 2016. Statistical analysis method of incremental dynamic analysis curves based on Bayesian methodology . Building Structure(03): 44-48.

[4] Zhou X L.2014. Research on Seismic Performance Evaluation Method of Earthquake Damaged RC Frame Structures . Chongqing University.

[5] Zhou X L\&Li Y M. 2014. Determination method of numerical analysis models of earthquake damaged reinforced concrete frame structures China Civil Engineering Journal . 47(S2): 280285. 